\title{
Auricular seroma: a new concept in management
}

\author{
Monika Shamrao Malgonde', Manoj Kumar² \\ ${ }^{1}$ Department of ENT, Mahatma Gandhi Institute of Medical Sciences, Sevagram, Wardha 442102, Maharashtra, India. \\ ${ }^{2}$ Department of Orthopedics, Lilavati Hospital and Research Centre, Mumbai 400050, Maharashtra, India.
}

Address for correspondence: Dr. Monika Shamrao Malgonde, Department of ENT, Mahatma Gandhi Institute of Medical Sciences, Sevagram, Wardha 442102, Maharashtra, India. E-mail: monika@mgims.ac.in

\begin{abstract}
Aim: Auricular seroma is a cystic swelling with a collection of serous fluid between the perichondrium and cartilage. The successful treatment of auricular seromas remains a challenge because this disease has a high propensity for recurrence. Methods: A total of 20 patients with auricular seromas were treated by remodeling a corrugated rubber drain. Results: All patients tolerated the procedure well. No patient had any collection of fluid after the removal of the splint. No patient experienced pain, fever, or edema after treatment. The seroma disappeared without disfigurement. There were no recurrences on further follow-up. Conclusion: Aspiration and splint application by remodeling a corrugated rubber drain provides very simple, minimally invasive, and effective management of seromas. It is a cost-effective treatment that prevents patient distress from fluid recollection and social embarrassment.
\end{abstract}

Key words:

Auricular seroma, remodeling, corrugated rubber drain

\section{INTRODUCTION}

Auricular seroma is a cystic swelling with a collection of serous fluid between the perichondrium and cartilage. It is usually in the upper part of the auricle. Seromas can develop spontaneously or after surgery or trauma (primarily blunt trauma) to the ear. An amber or straw-colored fluid is sometimes aspirated. Depending on the nature of the swelling and symptoms, auricular seromas can be distinguished from other lesions of the pinna. ${ }^{[1]}$ Successful treatment of auricular seromas is challenging because of their high propensity for recurrence. We propose a very simple, effective management of seromas by remodeling a corrugated rubber drain.

\begin{tabular}{|l|l|}
\hline \multicolumn{2}{|c|}{ Access this article online } \\
\hline Quick Response Code: & Website: \\
\hline & www.parjournal.net \\
\cline { 2 - 3 } & \\
\hline & DOI: \\
\hline
\end{tabular}

\section{METHODS}

Between May 2010 and August 2013, we treated 20 cases of auricular seromas at the Mahatma Gandhi Institute of Medical Sciences (Sevagram, India). No patient had any history of insect bites or any other medical illness. One patient had a definite history of blunt trauma to the ear; it was a nontender fluctuant swelling.

All seromas were drained by aspiration using all aseptic precautions [Figure 1]. The corrugated rubber drain was cut and shaped in accordance with the site of the seroma. Using 3-0 silk, the remodeled piece of corrugated rubber drain was fixed through the cartilage using a single suture [Figure 2]. Antibiotic ointment was topically applied, but no dressing was applied. The patient was administered with oral antibiotics and oral anti-inflammatory drugs. After 3 days, the patients were reviewed and the splint was removed. For the next 7 days, the patients were followed-up for any recurrence.

\section{RESULTS}

Of the 20 patients, 18 patients were males and 2 patients were females. Thirteen patients had swelling in the right 
ear and seven patients had swelling in the left ear. The mean age of the patients at presentation was 23.9 years. The most common complaint was external deformity, followed by pain ( 2 patients). Table 1 lists the sites of the seromas.

Of the 20 patients, 2 patients had already been treated with aspiration and bandage, but they presented with recollection. The exact cause of the seromas was unknown, except for 1 patient in whom there was a definite history of blunt trauma to the ear while playing.

All patients tolerated the procedure well. They were followed-up every 7 days up to 21 days. After 3 days, the splint was removed. None of the patients had any collection of fluid or experienced any pain, fever, or edema. The seroma disappeared without disfigurement. Further follow-up showed no recurrences. The patients were reviewed subjectively for the cosmetic impact of the treatment. We found that they were satisfied with the treatment since there were no dressings, which prevented social embarrassment. It was cosmetically acceptable [Figure 3].
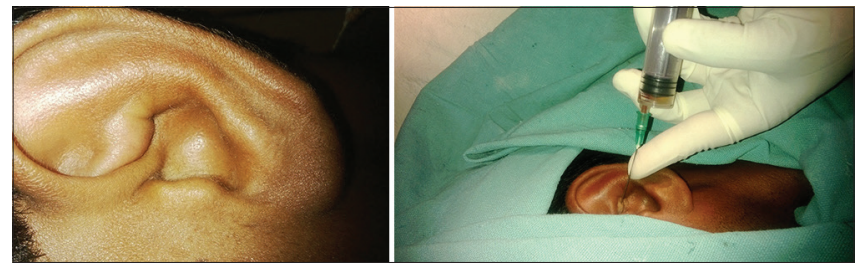

Figure 1: Aspiration and drainage of the seroma
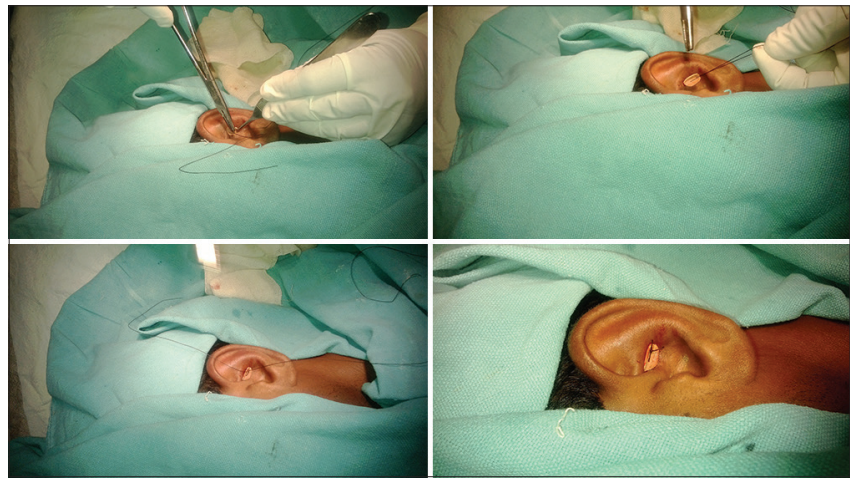

Figure 2: Placement of the corrugated rubber drain
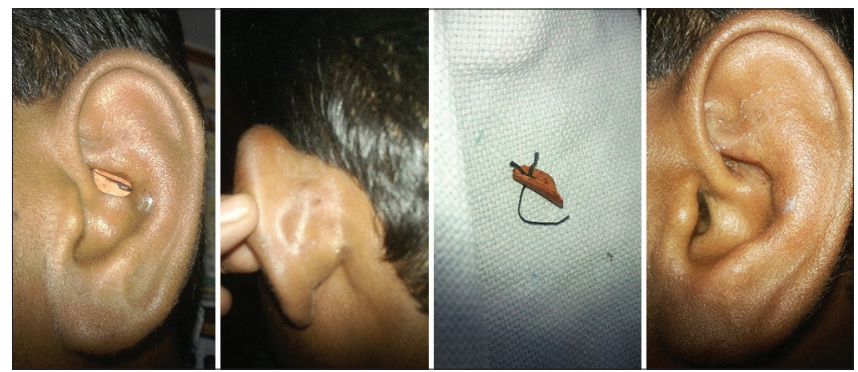

Figure 3: The pinna on follow-up

\section{DISCUSSION}

The successful treatment of auricular seromas remains a challenge because this disease has a high propensity for recurrence. Seromas are usually drained by aspiration and a compression bandage is applied. It is difficult to maintain molded pressure bandages on both sides of the pinna in place long enough to effectively prevent recollection. Many patients have a recollection and the bandage causes social embarrassment. Ghanem et $a .^{[2]}$ found recurrence of seromas after aspiration and bandage. Various other treatment modalities have been practiced such as applying pressure splints using coat buttons, achieving compression using cotton wool bolsters, and using silicone rubber splints. The limitations of these modalities include their availability and pliability. O'Donnell and Eliezri ${ }^{[3]}$ suggest excising a disc of cartilage and perichondrium to cure recurrent seromas. Placement of a continuous portable suction drain that remains at the incision site is a treatment option that has been advocated. ${ }^{[4]}$ Mattress or quilting sutures are applied in anatomical grooves to achieve compression more evenly after primary aspiration. ${ }^{[5]}$ The intralesional injection of triamcinolone as a treatment option for auricular seromas has also proven useful. ${ }^{[6]}$ A review of the literature suggests that 19-gauze stainless steel wire and chemically cured resin have been used to fabricate a pressure appliance to prevent recurrence. ${ }^{\mid 7]}$

We have proposed a very simple and effective management of seromas using aspiration and applying a splint formed by remodeling a corrugated rubber drain. A corrugated rubber drain has many advantages. A corrugated rubber drain is firm and easily available. It can be remodeled so that it fits into the small depressions of the pinna. It is pliable and can be shaped in accordance with the site of the seroma. This drain is fixed with a single suture, which splints adequately. No dressings are required and no complications have been noticed. This method is a minimally invasive procedure that is simple and effective. It also prevents patient distress from recollection, treatment, and social embarrassment. It is also cost-effective. This treatment can be administered to large seromas by using a single suture. A corrugated rubber drain is a treatment option in a rural setting where the availability of resources limits the treatment options. Most patients prefer not to make repeated visits to an outpatient department. This type

Table 1: Site distribution of the seromas

\begin{tabular}{lc}
\hline Site & Number \\
\hline Between the antihelix and cymba concha & 11 \\
Concha & 5 \\
Between the helix and antihelix & 3 \\
Multiple & 1 \\
\hline
\end{tabular}


of treatment is simple and effective. To prevent auricular cartilage infections, it has been suggested that seromas should not be aspirated in an outpatient department. However, our simple procedure can be performed with no complications in an out-patient department, provided it is performed under aseptic conditions and precautions are maintained.

\section{REFERENCES}

I. Kikura M, Hoshino T, Matsumoto M, Kikawada T, Kikawada K. Auricular seroma: a new concept, and diagnosis and management of 16 cases. Arch Otolaryngol Head Neck Surg 2006; 132 : I I 43-7.

2. Ghanem T, Rasamny JK, Park SS. Rethinking auricular trauma. Laryngoscope 2005; II5:125I-5
3. O'Donnell BP, EliezriYD. The surgical treatment of traumatic hematoma of the auricle. Dermatol Surg 1999;25:803-5.

4. Eliachar I, Golz A, Joachims HZ, Goldsher M. Continuous portable vacuum drainage of auricular hematomas. Am J Otolaryngol 1983;4:141-3.

5. Naik K. Seroma of the auricle: opening new doors over window. Int J Otorhinolaryngol Clin 201 I;3:88-9.

6. Bage AM, Bage NN, Anand KD, Vijayasundaram. Pseudocyst of the auricle: management options. Natl J Clin Acad 20 I 2; I: I8I-5.

7. Purwar A, Shetty $\mathrm{V}$, Khanna S, Gupta S. Pressure appliance to prevent the recurrence of auricular seroma: a new clinical trial.J Oral Biol Craniofac Res 2013;3:42-4.

How to cite this article: Malgonde MS, Kumar M. Auricular seroma: A new concept in management. Plast Aesthet Res 2014;1:13-5.

Source of Support: Nil, Conflict of Interest: None declared.

Received: 30-01-2014; Accepted: 28-05-2014 